\title{
GRADUATED THESIS AS A CHALLENGE FOR MASTER'S STUDENTS: THE CASE OF R. GLIER KYIV MUNICIPAL ACADEMY OF MUSIC
}

\section{a OLHA ZHORNOVA, ${ }^{\mathrm{b} O L E N A ~ Z H O R N O V A, ~}{ }^{\mathrm{C} O L E N A}$ VASYLIUK, ${ }^{\mathrm{d}}$ TETIANA KRYVOSHEIA, ${ }^{\mathrm{e}}$ VOLODYMYR HUMENIUK}

${ }^{A, b, c, e,}$ R. Glier Kyiv Municipal Academy of Music, Kyiv, str. L. Tolstoy-31, 01032, Ukraine

${ }^{d}$ Petro Tchaikovsky National Music Academy of Ukraine, Kyiv, str. Architect Gorodetsky, 1-3/11, 01001, Ukraine email: ${ }^{a}$ zhornova@ukr.net, ${ }^{b}$ acadmonex@gmail.com, cvasyliuk_helen@ukr.net, ${ }^{d}$ plato3@ukr.net,

et_gumenyuk@ukr.net

Abstract: This study examines the practice of writing graduated theses by students who have participated in music competitions. The reng garch med was a focus grents who have participated in music competions. The research method was a focus group. The reasons for this practice are described. It is proved the student cannot comply with the prescribed procedure for writing graduated these. It is concluded hat it is time to gextizence, its Measures to legitimize this practice are proposed.

Key words: graduated theses, writing of graduated theses, student, supervisor, legitimization.

\section{Introduction}

\subsection{Abbreviations and terms}

Abbreviations and terms in the article:

HEI is a higher education institution.

GT is graduate theses.

A performer is the qualification "Performer - musician - soloist" of graduates of the master's program of the Glier Kyiv Municipal Academy of Music.

C\&A is International/World competitions and auditions.

The research procedure is writing graduate theses, which the higher education institute proved.

\subsection{The background of this study}

The background of this article was the situation that happened during the defense of GT in the department of Humanities and Music-Innovative Disciplines of R.Glier Kyiv Municipal Academy of Music in 2019. The two best GT were highlighted during the collective discussion. As it turned out, the authors of these theses followed the research procedure differently.

The theme for the first GT was chosen from the list of GT themes recommended by the department. It showed the peculiarities of teaching school children to sing pop songs. GT pleasantly impressed us with the carefully collected educational and methodical materials and their adaptation for application. The author strictly adhered to all the research procedure regime points during the time allotted for GT. This writing GT is a classic example of full compliance with the research procedure.

The student herself proposed the topic of the second GT. This GT studied exploring the experience that the students of musical HEI acquired due to participating in music TV shows. It is interesting because

- describes in detail the author's history of participation in the TV show "Voice of the Country,"

- includes unknown empirical data that the author collected during the survey other participants similar TV shows (the author herself developed the questionnaire),

- offers original recommendations:

(a) to teachers of musical HEI - regarding the usage of TV show potential in the educational process;

(b) to students - concerning career formation of a pop singer;

(c) to TV show organizers - the best way of communication with the academic community of the profile HEI.
The author, who constantly participated in various C\&A, tried to adhere to control educational activities. She always "vibrated" from the timetable to communicate with the supervisor and complete research tasks.

This article's research procedures mentioned above are Ostinato and Ad Libitum, respectively. The terms are commonly known to any musician. Ad Libitum means an opportunity to perform music work freely, as a performer desires, and, as a rule, such a way of performing is short-lived and applies only to a single fragment of the work. Ostinato is multiple repetitions. This way of performing plays an essential role in shaping music work. So the same goal of Ostinato and Ad Libitum is achieved differently: Ostinato is in full compliance with the research procedure, while Libitum is a departure from the established regime and substantive guidelines.

The discussion showed the necessity of studying the current situation in writing GT. We decided to investigate the problem of the legitimization of Ad Libitum.

\section{Frame of The Study}

First of all, we were interested in how widespread Ad Libitum is. Talking to the supervisors of the other HEIs, we have made sure they are also facing Ad Libitum. They also support it because they understand that C\&A is an integral part of the training process for performers and the most crucial part of a master's degree experience that cannot but influence the research procedure.

Those conversations were private and cannot be the basis for the legitimization of Ad Libitum. By now, colleagues do not have scientific information about Ad Libitum and do not understand its problems. We decided to study the scientific literature on the peculiarities of writing GT by students of the music master's program.

At present, we do not currently know the study of the impact of $\mathrm{CA}$ on research, the consequences of violating the research procedure, the complexity of combining participation in CA and writing GT. Scientists make the problems wider. Existing educational programs need to be improved to meet the demands of the modern labor market, which allows only a high level of preparation (Wright \& Osman, 2018; Sagy et al., 2019).

There are significant results of several foreign studies devoted to optimizing master music programs in this context. Harrison and Grant (Harrison \& Grant, 2016) recommend better preparation music students for life beyond their studies. So they are advocating, in particular, a more collaborative model of research education than the one that is currently the norm. Other authorities (Convay et al., 2021) say that all program directors are aware of the varied needs of program graduates. Their work suggests that using varied tracks and choices for degree completion are desirable. It is noteworthy that for some graduates of master's programs, scientific work acquires great importance and becomes an essential part of their master's experience (Conway et al., 2009).

Another aspect of master-programs improvement is the introduction of new training performers. For example, Dorfman is convinced that distance music education, which is likely to grow in the coming years, deserves special consideration (Dorfman et al., 2021).

The improvement of the music master programs cannot but affect supervision practice. Many researchers agree that the traditional role of the supervisor needs to be redefined.

On the one hand, it is emphasized that clear organization and continuous monitoring focus on tasks impact better learning 
outcomes and promote faster completions. Zhang and Jiang (Zhang and Jiang, 2021) propose strengthening the supervisor's responsibility, up to an evaluation of the supervisor's work, and believe that it is needed to make regular reports and discussions on research progress and feedback on research progress, and experience over a certain period. It's even suggested that it is a need that should be addressed by policymakers and the management at universities as a matter of the utmost urgency (Brink, 2021).

On the other hand, strong arguments are increasingly heard in defense of a different form of supervision practice, conventionally called the 'non-interference' regime (McCallin and Nayar, 2012).

So consideration should also be given to the most appropriate time for introducing support mechanisms without overburdening already overworked supervisors and students. Liezel Massyn raises this problem (Massyn, 2018).

The practice requires supervisors to envision a more far-reaching research prospect, not just the public protection by students of the research undertaken. However, supervisors have difficulty in determining such opportunities. Researchers concluded that most of the intentions underlying supervision practice were related to the concepts of 'acculturation' and 'functionality,' much less to the concepts of 'preparation for work and life' (Kreber and Wealer, 2021).

It should be borne in mind that the challenges mentioned above to the supervision are inseparable from the attendance policy. The attendance policy is based on general rules and requirements that do not depend on the nature of HEI. However, each HEI has the authority to correct the attendance policy, considering the specifics of educational programs implemented.

The difficulties of scientific substantiation of the attendance policy arise because, at present, there is no established law between student visits and student achievements. Büchele concludes, after conducting the study, that results of student achievements do not depend on how students attend class. Moreover, he questions the proposition that "in general, studies find positive but mostly weak correlations between attendance and performance“ (Büchele, 2021).

The study of Massingham and Herrington is very indicative. On the one hand, they note that students who attended lectures and tutorials had a better chance of having higher marks on all assessment tasks, particularly in the final examination. On the other hand, the authors add concerning Rodgers that "even though students increased their attendance through an incentive scheme, performance remained the same.“ (Massingham and Herrington, 2006).

In our opinion, it is more appropriate to speak that the attendance reflects the level of student involvement in their course and is critical to student success (Moores et al., 2019). Therefore, the proposal to implement an attendance policy that encourages students to attend classes seems quite balanced (Karnik et al., 2019).

This study is focused on resolving the contradiction between the actual practice diverged from the provisions in the research procedure and the constant requirements or overarching standard for offering how to write GT.

\section{Research method}

The research method was a focus group. Two Peer Groups were held in December 2019.

They are based on the premise that the personal perceptions of the educational process by master's students and supervisors are a compelling reason to make the right decisions on the learning environment, study programs, and paths. (Hattie, 2009, 2015; Hattie and Gan, 2011; Hattie and Timperley, 2007).
The first group consisted of five master's students (2 men and 3 women between 22 and 27). They had their history of participation in national and/or international C\&A. At the time of the focus group, and they had already successfully defended their GT.

The second group consisted of five supervisors ( 1 man and 4 women between the ages of 45 and 67); there were 2 doctors of science, professors; 2 candidates of science, associate professors; 1 Honored Art Worker, Associate Professor. All the participants had the experience of working as a supervisor no less than 5 years and scientific-pedagogical experience no less than 15 years.

Each focus group operated for two hours. At the beginning of work, we announced that we were studying the best practices of GT for the good of other students. We informed the participants that:

- We want to know what they like and dislike about the research procedure and improve existing practices.

- Both negative and positive comments are crucial because sometimes negative comments are more informative.

- They should give individual examples of how students wrote the GT and the quality.

We clarified to the supervisors that these cases must relate to their recent experience, usually defined as being within the previous three years.

At the end of the discussion, we asked participants to recall everything said and express their views, central to improving the research procedure. We asked students to answer the following question: "Of all the things we discussed, what is the most important for the good of students who take part in C\&A?" For supervisors, the question was formulated as follows: "Suppose you have the opportunity to change the practice of supervision. What would you do?"

Finally, the proposed issues did not mention different types to avoid unnecessary navigation on significant differences in the research procedure.

\section{Finding and discussions}

The first group participants most discussed issues were related to students' failure to stick to the regime points. The students think it is difficult and sometimes impossible to attend all contact hours and carry out the tasks assigned by the supervisor on time.

"What shall you do? You have unexpectedly been called to have a rehearsal for the time when your next consultation with your research adviser must be. You realize that it is impossible to let the team down, but to miss consultations is also undesirable."

"GT had turned out to coincide with the time of my preparation for participation in the international competition. This competition was very important for my career as a professional performer. Of course, all thoughts had been focused on rehearsals as much as possible. I couldn't think of anything else. And then, when the competition had been over, it was necessary to catch up with the schedule of GT. Everything, however, ended well, though it was not easy to do. But I think I had done the right thing - I had focused on the competition because I hadn't wanted anyone to believe that Ukraine is incapable of bringing up a good musician."

Students consider it reasonably sufficient to work on their research at the breaks between rehearsals, concerts, competitions.

"I think that a flex-time work on research is very appropriate. I can work on my GT anywhere if I have free time, but, you know, I can not perform anywhere and anytime (the student wants to say that he can not change places and dates of his performances 
- authors). I think many of my colleagues that take part in competitions think the same way."

"We all know that a good musician participates in competitions in competitions, auditions, festivals, concerts. Even the World Federation of International Music Competitions website claims that the competition is the key to success and career. Students should be allowed to participate in competitions, and supervisors should change different deadlines and graphics for such students".

Students' violation of the regime points is also a problem for supervisors, but it is not a priority. The supervisors understand that students' participation in C\&A is often a direct impediment to regular contact and classroom hours.

"I am used to the fact that the dates and times for rehearsals and concerts sometimes coincide with the dates and times for GT consultations. I'm always interested in how these musical events happen. We even discuss the situations that took place there".

The supervisors understand that students' participation in C\&A is often a direct impediment to regular contact and classroom hours.

"I am convinced that students respect us and the visiting policy. But they can't deal with a situation where the GT and the contest coincide".

According to the supervisors, not adhering to the regime points is a matter of professional development of the performer over discipline. The main challenge facing supervisors is choosing the topic of GT. They noted that most students choose a topic from the list offered by the department. Nevertheless, quite often, the participants of C\&A insist on researching «their own» topic. The supervisors confirmed that those students often perceive a topic from the list as the embodiment of someone else's plan.

"If you do not convince students of the advantages of the WR topic from the list, they will insist on their topic. It seems to them to be the most relevant and most interesting. Although they have not even started to search for scientific sources".

In this case, the supervisors realize that managing the work of such a student is much more complicated and stressful.

"One who once agreed to manage a topic that is not from the list knows that it is a burden. You must find and process much literature on this new topic and compile a bibliography. Then you have to discuss the bibliography with colleagues etc. So if you agree to do it one more time, that probably means you love the challenge."

However, all the supervisors still agreed with the point made by one of them: "We must allow students to study the topic they like. The list of topics for GTs offered by the department should be treated as a recommendation, but no more."

We noted that the willingness to support a student's choice must always be justified. So, the supervisors are convinced that the opportunity to investigate the topic offered by the student positively influences his desire to engage in scientific work after graduation from the HEI.

"The more we support a student's researching of his or her topic, the more likely the student will continue the research in the future."

"If I know that a student's choice is not random and not a manifestation of his or her fleeting passion, I'm prepared to support it. However, the students themselves have to understand the difficulties they will face in the future."

All supervisors noted that active participants of C\&A were more convinced of their high readiness to GT and often underestimated the complexity of research and overestimated their own experience.
"They were sure that we were trying to exaggerate the difficulties of GT."

At the same time, such students often are not prepared to spend much time formulating it and justifying its relevance.

"Although the student confessed to me later: I did not think that if I had chosen a topic of interest, it would have caused additional difficulties. Maybe if I knew that, I wouldn't have been so insistent on studying my subject ".

It was impressive that the participants were unanimous in regulating the alternative research procedure, which would at the same time enable students to participate in the competitions and ensure the high quality of the GT. It was called in various ways: flexible, free, modern, alternative, etc.

"Our students are mainly responsible, but, above all, they pay all their attention to the realization of themselves as performers. They perceive all other activities, particularly scientific research, as a deviation from the 'business of life.' Such situations usually arise when students have a strong internal positive motivation to participate in C\&A, professional contests as often as possible. That is why we can reach a flexible schedule of contact hours. It should not be called violation."

"If a free procedure is legal, it will be possible to resolve the urgent difficulties. Over time, the process of theoretical understanding of other practice of supervisor will begin, and its advantages will undoubtedly be appreciated by those colleagues who have progressive views on the pedagogical process."

"Free implementation of research is necessary for the development of professional competence of the performer. This should be solved in the following way: allow this new practice in addition to the traditional practice. However, first of all, there should be a broad discussion of what is meant by another research procedure."

"It is impossible to envisage all the auditions and performances in which students will take part. Using flex-time organization, there are possibilities not to betray their "business of life" and to fulfill their theses at a decent level."

Students are concerned that their participation in the competitions may negatively affect the reputation of the supervisors.

"The competition and the PB are not opposed but coincide in time. And the supervisor needs to have legal grounds to support a student when he's not doing his current assignments on time. 'Cause, it turns out the superintendent is supporting me, and I'm putting him in a tough spot."

"Understanding the situation, supervisors will not create obstacles to our improvement of performance skills. Nevertheless, it is a very difficult and uncertain decision for a supervisor to support students who have to use flex-time work."

Neither supervisors nor students discovered the connection between the result of GT and compliance with the prescribed research procedure. So the problem of providing quality assurance of GT should not be reduced to compliance with procedure, especially the timetable on the communication with the supervisor and for the completion of research tasks.

So the decision to comply with Ostinato means not participating in C\&A. The decision to be an active participant of C\&A means not to comply with Ostinato. The choice of decision is based on the meaningful self-identification of students. If students regard themselves as artists, they choose C\&A and Ad Libitum. If a student's academic activity remains the leading one, they decide in favor of Ostinato. 
The supervisor's support of the student's choice is, in fact, the confirmation by the supervisor of the student's selfidentification. The requirements for writing GT do not meet the expectations of the students who think that this kind of educational training will be inspiring and not onerous. Only over time, of course, do they realize that scientific research is a task that requires a great deal of effort and sometimes not less than participation in C\&A.

\section{Conclusions}

The study confirmed the existence of two opposite types of research procedures. Moreover, Ad libitum results from the inability to follow the Ostinato. At first, perceived as a situational "way out," Ad libitum gradually begins to exist as a new procedure that overcomes the limitations of Ostinato. Maybe it is time to legitimize Ad Libitum.

The reasons for the legitimization of Ad Libitum are

- the recognition of the existence of Ad Libitum,

- the acceptance of it by both students and supervisors,

- the positive effect of using it.

The key message of the legitimization of Ad Libitum is the affirmation of the value of scientific, organizational, and other students' and supervisors' initiatives that help reduce confrontation between C\&A and GT.

Thus, we expect Ad Libitum will maximize the benefits of participating in C\&A and minimize the costs due to violation of Ostinato.

We should note that the legitimization of Ad Libitum is consistent with the principles of HEI, which are in article 32, "Principles of operations, main rights and responsibilities of a higher education institution" by Law of Ukraine "About higher education" (https://zakon.rada.gov.ua/laws/show/155618/stru?lang=en)

Activities to legitimize Ad Libitum can be implemented in a particular department, faculty, or university. The advantage of legitimization at the status of a department or a faculty is that a student's research experience is well known to the supervisors of this department. If members of the Scientific Council receive positive feedback about Ad Libitum from students and supervisors, they can legitimize Ad Libitum at the university. Being legalized, Ad Libitum will be supported by material, financial and other resources, and management will resolve the issue of training of supervisors.

In addition, it is worth adding that there is a necessity to discuss the introducing mechanisms of Ad Libitum (benefits, credits, voluntary agreements, requirements, etc. and debate which of these mechanisms are more effective.

We emphasize that Ostinato and Ad Libitum, considered in this study, are the research procedure's limited types. Ostinato is a full observance of all regime points, and substantive guidelines of the GT and Ad Libitum are a complete violation of them. Without a doubt, there are cases where intermediate types exist, for example, a partial observance of regime points and full observance of substantive guidelines of the research procedure.

We hope that in conditions when the global labor market requires the highest level of skill, the issues of legitimizing Ad Libitum will give rise to a scientific discussion about the specifics of involving future performers in the process of scientific research.

Limitations. More probabilistic results will be obtained in the case of a larger sample of respondents from different HEIs and the application of other methodologies and research methods.

\section{Literature:}

1. Brink, E. (2021). The roots of the lack of masters and $\mathrm{PhD}$ supervisors. Monday 15 February | 2021. https://jouloopbaa n.solidariteit.co.za/en/the-roots-of-the-lack-of-masters-and-phdsupervisors/

2. Büchele, S. (2021). Evaluating the link between attendance and performance in higher education: the role of classroom engagement dimensions, Assessment \& Evaluation in Higher Education, 46:1, 132-150, DOI: 10.1080/02602938.2020.175 4330)

3. Conway, C. M., Eros, J., \& Stanley, A. M. (2009). Perceptions of master's graduates regarding the effects of the master of music in music education program on P-12 teaching practice. Research Studies in Music Education, 31(2), 1-13. http://doi .org/10.1177/1321103X09344381

4. Conway, C., Vaughan-Marra, J. \& Marra, C. (2021). Balancing the Varied Needs of Master of Music Education Students: Perceptions From Program Directors and Alumni. Journal of Research in Music Education, 69(1),105-120. doi:10.1177/0022429420951953

5. Dorfman, J., Matthews, W. K., Resta, G. \& Venesile, Ch. (2021). Looking Into the Virtual Space: Teacher Perceptions of Online Graduate Music Education. Bulletin of the Council for Research in Music Education, 229, 71-90, https://www.jstor.org /stable/10.5406/bulcouresmusedu.229.0071

6. Harrison, S., \& Grant, C. (2016). Chasing a moving target: Perceptions of work readiness and graduate capabilities in music higher research degree students. British Journal of Music Education, 33(2), 205-218. doi:10.1017/S0265051715000261

7. Hattie, J. (2009). Visible learning: a synthesis of over 800 meta-analyses relating to achievement. Park Square, OX: Rutledge.

8. Hattie, J. (2015). The applicability of visible learning to higher education. Scholarship of teaching and learning in psychology, 1(1), 79.

9. Hattie, J., \& Gan, M. (2011). Instruction based on feedback. In Handbook of research on learning and instruction (pp. 263285). Routledge.

10. Hattie, J. \& Timperley, H. (2007). The Power of Feedback. Review of Educational Research, 77:1, 81-112. DOI: 10.3102/003465430298487

11. Karnik, A., Kishore, P., \& Meraj, M. (2020). Examining the linkage between class attendance at university and academic performance in an International Branch Campus setting. Research in Comparative and International Education, 15(4), 371-390. https://doi.org/10.1177/1745499920958855

12. Kreber, C. \& Wealer, C. (2021). Intentions, concepts and conceptions of research supervision: a consideration of three disciplines. Teaching in Higher Education. DOI: 10.1080/13562517.2021.1900815

13. Massingham, P. \& Herrington, T. (2006). Does Attendance Matter? An Examination of Student Attitudes, Participation, Performance and Attendance. Journal of University Teaching \& Learning Practice, 3(2). Available at: http://ro.uow.edu.au/jutl $\mathrm{p} / \mathrm{vol} 3 /$ iss $2 / 3$

14. Massyn, L. (2018). Enhancing completion rates of minidissertations for a professional master's degree: An integrated approach, The International Journal of Management Education, 16:1, 114-120. https://doi.org/10.1016/j.ijme.2018.01.002

15. McCallin, A. \& Nayar, Sh. (2012. Postgraduate research supervision: a critical review of current practice, Teaching in Higher Education, 17:1, 63-74, DOI: 10.1080/13562517.20 11.590979

16. Miller, J., \& Baker, D. (2007). Career orientation and pedagogical training: Conservatoire undergraduates' insights. British Journal of Music Education, 24(1), 5-19. doi:10.1017/S0265051706007194

17. Moores, E., Birdi, G. \& Higson, H. (2019). Determinants of university students' attendance, Educational Research, 61:4, 371-387, DOI: 10.1080/00131881.2019.1660587

18. Sagy, O., Hod, Y. \& Kali Y. (2019). Teaching and learning cultures in higher education: a mismatch in conceptions. Higher Education Research \& Development, 38:4, 849-863, DOI: 10.1080/07294360.2019.1576594 
19. Wright, E. \& Osman R. (2018). What is critical for transforming higher education? The transformative potential of pedagogical framework of phenomenography and variation theory of learning for higher education. Journal of Human Behavior in the Social Environment, 28:3, 257-270, DOI: 10.1080/10911359.2017.1419898

20. Zhang, Y.T. \& Jiang, Y.L. (2021). Investigation and Analysis on the Cultivation of Academic Competence of Postgraduates. Open Access Library Journal, 8, 1-12. doi:10.4236/oalib.1107967

\section{Primary Paper Section: A}

Secondary Paper Section: AM 